\title{
LITERATURA
}

\section{Literatura em 2004}

0 ano de 2004 foi rico para a literatura brasileira. Obras de centenas de autores foram lançadas em feiras e eventos espalhados por todo o país. Esse esforço contribuiu decisivamente para a diversificação e desenvolvimento de nossa cultura literária. Ricardo de Mattos, advogado e colunista do Digestivo Cultural, apresenta neste ensaio crítico escritores de todo o país, destacando autores de antologias e obras que abordam temas como cultura regional e história dos costumes.

ocioso e causa certa agonia ao leitor ativo relembrar a infinidade de bons, ótimos e excelentes títulos com os quais ele foi presenteado no ano de2004. Partindo do Rio Grande do Sul, apontam-se os mui festejados Longe da água, de Michel Laub; Cinco M arias, de Fabrício Carpinejar; além de Berkeley em Bellagio e M ínimos múltiplos comuns, ambos de João Gilberto $\mathrm{N}$ oll, o segundo valendo-Ihe 0 prêmio Jabuti do ano. Alcançando 0 Sudeste, 0 aniversário de 450 anos da cidade de São Paulo rendeu vários livros, entre os quais A capital da solidão, escrito por Roberto Pompeu de
Toledo; Paulística, etc., por Paulo Prado; e Cosmópolis, por Guilherme de Almeida. 0 Nordeste foi muito bem representado com a reedição das obras de Gilberto Freyre - Sobrados e mucambos, Ordem e progresso, N ordestee de Câmara Cascudo - A história da alimentação no Brasil. No campo his- 
tórico, o predomínio foi de obras sobre o Brasil republicano.

0 interessado poderá confrontar os livros da série de Elio Gaspari A ditadura encurralada, cujo último volume, Visões do golpe - A memória militar de 1964, organizado por Maria Celina d'Araújo, traz depoimentos de militares que participaram ou testemunharam de perto o movimento. H ouve uma sal utar tendência de aproximar o leitor nacional da literatura de seus vizinhos, destacando, sobre todos, os livros Pedro Páramo \& Chão Em Chamas, do mexicano Juan Rulfo. A literatura russa continua surgindo aos poucos, sempre encabeçada pelas obras de Anton Tchékhov, Ivan Turguiêniev e Dostoiévski. Três romances deste último foram traduzidos: 0 eterno marido, 0 s demônios e Humilhados e ofendidos.

0 ano também foi bem servido de antologias. Entre as pessoais, mencione-se a póstuma Cinco histórias, de Jorge Amado. Dos autores felizmente vivos, citam-se 0 melhor das comédias da vida privada, de Luis Fernando Veríssimo, e As melhores crônicas, de Ignácio de Loyola Brandão. Entre as temáticas, três bons exemplos são as dedicadas aos contos escritos por mulheres. Contos de escritoras brasileiras, organizado por Vianna e Guidin; Feminino, com 11 contos originalmente publicados na Revista $E$, do Sesc; e 25 mulheres que estão fazendo a nova literatura brasileira, organizado por Luiz Ruffato. Os melhores papéis das antologias são justamente estes: apresentar nomes desconhecidos do público em geral, ou regional, e ventilar o espírito do lei-

A diversidade regional de lançamentos de novos e excelentes títulos nacionais foi uma das grandes marcas do setor literário no Brasil em 2004.

tor, convidando-o a conhecer novos temas e formas de escrita. Muitas vezes é o début dos novos escritores.

Uma antologia singular é a contida no volume intitulado Wunderblogs. com, reunindo o trabalho de 11 blogueiros brasileiros em atuação na internet. A hibridação de gêneros e 0 estilo extremamente pessoal faz com que se dividam as opiniões dos poucos leitores dessa escrita de alcance condominial. Um dos ramos da história dos costumes trata especificamente da leitura no passar dos séculos e tem na figura de Roger Chartier um de seus principais estudiosos e expositores. Em obras anteriores ele se ateve a analisar se 0 advento da internet teria decretado, ou viria a decretar um dia, o fim do livro impresso, fazendo o leitor comum trocar o suporte de papel pelo computador ou demais aparelhos destinados ao uso análogo e-book. Pode-se responder que, senem o livro virtual é ameaça efetiva, quanto mais páginas mantidas despreocupadamente por poucos indivíduos em suas horas vagas. São títulos lançados por autores que têm em comum a origem ou a adesão ao novo gênero: M orte e vida celestina, de Alexandre Soares Silva; Primavera eterna, de Paula Foschia - ambos da Candide Editora, até agora especializada em publicações desse estilo -; eVida de gato, de Clarah Averbuck.
O país de leitores. Os títulos citados trazem a in defectível pessoalidade da seleção. 0 ano de 2004 começou com uma Bienal, realizou novamente a Festa Literária Internacional de Paraty (Flip) e encerrou-se com a Primavera do Livro, organizada pela Liga Brasileira de Editores (Libre). Apenas na Bienal foram 2 mil lançamentos. Contudo, o estado do Ceará também promoveu um evento idêntico: que autores e que títulos fugiram lá ao nosso al cance? Sem contar a cinqüentenária Feira do Livro de Porto Alegre, a oitava Feira Pan-Amazônica do Livro promovida pelo governo do Pará, a quarta Feira Internacional do Livro Universitário... A profusão de lançamentos e festivais anima o leitor em especial, mas chega a ser de infeliz irrelevância diante do quadro nacional geral. Segundo o IBGE, o Brasil já conta com uma população superior a 182 milhões de habitantes. $\mathrm{Nem}$ todo o volume novo traz a tiragem, porém 3 mil é o número médio citado e aceito. $\mathrm{Na}$ Bienal, estimou-se em 2 mil 0 número de lançamentos. Cada lançamento de tiragem padrão revela um montante de 6 milhões de exemplares, suficientes para atender $3 \%$ da população. Essa porcentagem aumenta para 3,75\% se descontados $11,8 \%$ de analfabetos do total populacional. A situação continua precária, mesmo que haja um par de leitores para cada li- 
Se um dia o Brasil será um "país de leitores", a resposta depende dos rumos da educação e da mudança de mentalidade do brasileiro.

vro comprado. 0 jornal 0 Estado de S. Paulo de 16 de setembro de 2004 divulgou alguns dados da pesquisa encomendada pelo BNDES. Um dos mais marcantes é a revelação de que, entre os anos de 1993 e2005, a quantidade de exemplares vendidos caiu quase pela metade - $48 \%$. Ou seja, dos 6 milhões de exemplares aqui sumariamente computados, apenas metade é comprada.

Lamentavelmente, se muito contribuem, os eventos e seus esforços não são os responsáveis pela formação do sonhado "país de leitores". Se um dia o Brasil será esse país, a resposta depende dos rumos da educação e da mudança de mentalidade do brasileiro. 0 Estado, em seus três níveis, é o maior adquiridor de livros, mormente didáticos. Importa saber o que acontece com esses livros quando desembalados e arrumados nas estantes das escolas e universidades. São habitualmente compulsados, ou a demanda depende do período de provas? Q uem as seleciona são professores baseados no programa, ou bibliotecários baseados na demanda cotidiana? Da mesma forma, estará o brasileiro médio apto a selecionar autores e temas para estimular seus filhos na prática da leitura?

Esses dados, todavia, não obstam o crescimento do número de editoras. Grandes casas estrangeiras adentram o país trazendo o benefício da concorrência, e ganha quem oferece 0 meIhor título numa boa encadernação e pelo preço justo. A Editora Planeta vende nas bancas de jornais, por $R \$ 16$, livros de capa dura e bom pa- pel que poderiam alcançar até $R \$ 50$ nas livrarias. De qualquer forma, diante da fragilidade do mercado editorial do país, as editoras al ienígenas acabam por trabalhar ao lado - enão contra - as nacionais. Segundo a mesma pesquisa do BNDES, todas as editoras estabelecidas no país, juntas, vendem menos que a 13a editora mundial sozinha. É nesse mercado desfavorável que as pequenas editoras lutam arduamente para sobreviver. Geralmente escolhem uma de duas alternativas. A primeira e melhor caracteriza a Amauta e a extinta Paraula, editoras pequenas mas com um capricho de tradução e edição que beira 0 artesanal. A segunda é dedicar-se ao livro vendável, atitude que se justifica pela necessidade de manter-se, mas que permite que obras ruins, a exemplo da famigerada literatura de autoajuda, proliferem.

Ricardo de Mattos

Colunista do Digestivo Cultural

E-mail: louisxiv@uol.com.br

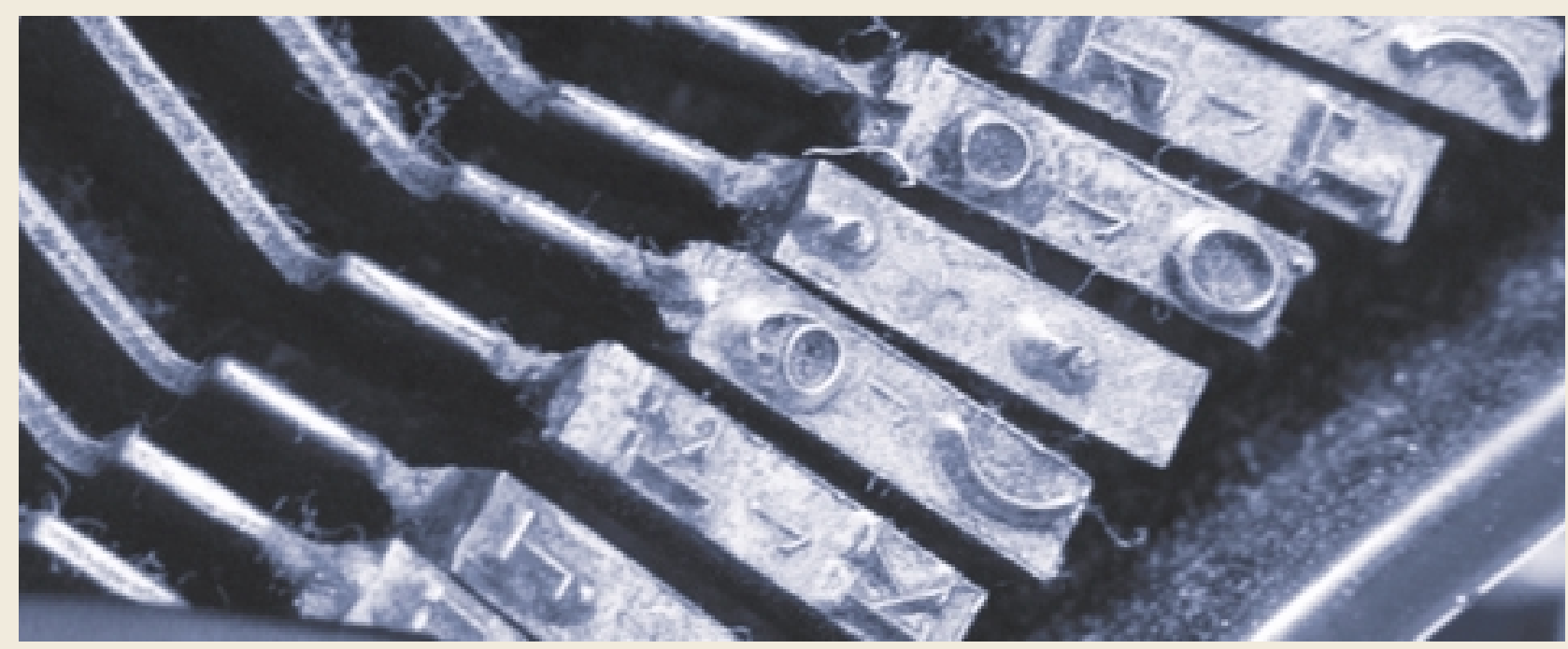

